Artikel Penelitian

\title{
Rancang Bangun Tungku Gasifikasi Tipe Counter-Flow dengan Bahan Bakar Biomassa Municipal Solid Waste (MSW)
}

\author{
Dendi Adi Saputra M, Adjar Pratoto, Andoni Prayogi
}

Jurusan Teknik Mesin Fakultas Teknik Universitas Andalas

INFORMASI ARTIKEL

Sejarah Artikel:

Diterima Redaksi: 04 Agustus 2017

Revisi Akhir: 01 September 2017

Diterbitkan: 31 Oktober 2017

\section{KATA KunCI}

\section{Stove}

Gasification

Counter-Flow

Efficiency

Design

\section{KORESPONDENSI}

E-mail: dendiadisaputra05@gmail.com

\section{A B S T R A C T}

This research discusses about designing of counter-flow type gasification stove utilizing biomass municipal solid waste (MSW). The first step of the research process is to formulate the design concept of the gasification stove using the MSW collected in Padang city. The results of the design concept formulation are used to obtain the detail design parameters which is used as the reference for manufacturing the stove. The main designing parameters of the gasification stove are the diameter and the height of the stove. The technical drawing is made according to the designing parameters obtained from the design concept formulation. Base on the technical drawing, the counter-flow type biomass gasification stove was built. The obtained results show that for a large value of updraft air and a small value of downdraft air, the operating time of the stove is long. This condition is obtained in the case of standard air and fuel ratio $(A F R<1.5)$. This results show that the gasification stove efficiency is better in comparison with the conventional one.

\section{PENDAHULUAN}

Pada saat sekarang ini kebutuhan energi dunia masih tergantung kepada pemanfaatan bahan bakar fosil seperti minyak bumi, gas alam ataupun batu bara. Kebutuhan energi dunia dari tahun ke tahun cenderung meningkat seiring dengan peningkatan jumlah penduduk di dunia. Penggunaan bahan bakar fosil sejak lama telah menipiskan persediaan bahan bakar fosil yang terdapat di dalam perut bumi. Bahan bakar fosil tidak dapat di daur ulang sehingga akibat penggunannya selama ini telah membuat ketersediaan bahan bakar fosil semakin menipis. Dengan demikian perlu dikembangkan suatu bentuk sumber energi alternatif yang ketersediaannya banyak dan dapat diperbaharui. Biomassa merupakan salah satu energi alternatif yang dihasilkan melalui proses fotosintetik dari bahan organik, baik berupa produk maupun buangan. Potensi biomassa di Kota Padang yang bisa digunakan sebagai sumber energi jumlahnya sangat melimpah. Salah satunya adalah Biomassa dari sampah padat perkotaan/ Municipal Solid Waste (MSW). Kehadirannya merupakan hal yang paling tidak disukai oleh seluruh masyarakat, karena memberikan banyak dampak buruk. Berdasarkan hasil penelitian Yenni Ruslinda, Veronika [1], menunjukkan rata-rata sampah industri Kota Padang sebesar 5,057 kg/orang/hari atau 0,164 $\mathrm{kg} / \mathrm{m} 2 /$ hari dalam satuan berat atau 6,569 liter/orang/hari atau 0,441 liter/m2/hari dalam satuan volume. Sumber sampah yang memberikan 


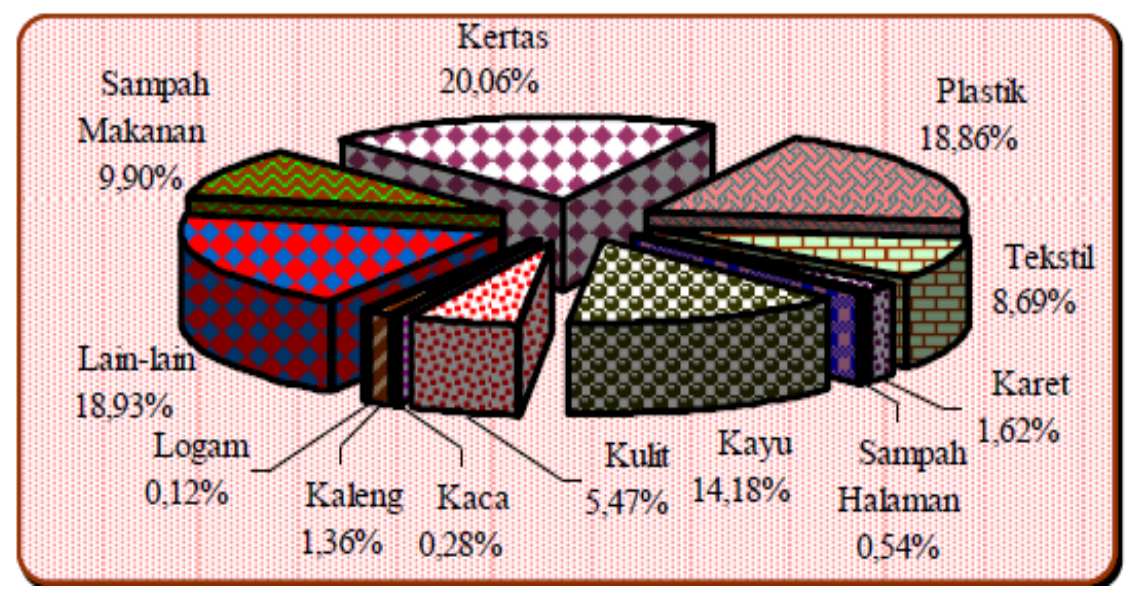

Gambar 1. Komposisi Sampah Industri Kota Padang [1]

kontribusi terbesar berasal dari sampah industri besar dengan timbulan 9,606 liter/orang/hari, diikuti sampah industry sedang (5,644 liter/orang/hari), dan penghasil sampah terkecil adalah industri kecil (4,457 liter/orang/hari). Semakin besar kategori industri (semakin banyak jumlah karyawan) maka semakin besar jumlah timbulan sampah yang dihasilkan.

Komposisi sampah industri Kota Padang didominasi sampah organik $79,31 \%$ yang terdiri atas sampah makanan $9,90 \%$, kertas $20,06 \%$, plastik $18,86 \%$, tekstil $8,69 \%$, karet $1,62 \%$, sampah halaman $0,54 \%$, kayu $14,18 \%$, dan kulit $5,47 \%$. Sedangkan sampah anorganik $20,69 \%$ terdiri dari kaca $0,28 \%$, kaleng $1,36 \%$, logam $0,12 \%$, dan lainlain (campuran tanah dan serbuk gergaji, busa) sebesar 18,93\%. Penghasil sampah organik terbesar adalah industry sedang 95,66\% diikuti industri kecil $92,37 \%$, dan terakhir industri besar 49,89\%. Gambar 1 memperlihatkan komposisi rata-rata sampah industri Kota Padang. Berdasarkan data di atas serta kalkulasi perkiraan jumlah sampah/hari di kota Padang, maka terdapat potensi pemanfaatan biomass dari sampah padat perkotaan/ municipal solid waste (MSW) menjadi energi terbarukan dengan metode gasifikasi. Teknologi gasifikasi biomassa merupakan suatu bentuk konversi energi yang terkandung di dalam biomassa. Proses gasifikasi berlangsung di dalam suatu reaktor yang disebut gasifier. Pada alat ini bahan bakar biomassa diurai di dalam reaktor (ruang bakar) dengan udara terbatas. Dengan kata lain, proses gasifikasi biomassa merupakan proses pembakaran tidak sempurna bahan baku padat biomassa, melibatkan reaksi antara oksigen secara terbatas dengan bahan bakar padat berupa biomassa. Uap air dan karbon dioksida hasil pembakaran direduksi menjadi gas yang mudah terbakar, yaitu karbon monoksida $(\mathrm{CO})$, hidrogen $\left(\mathrm{H}_{2}\right)$ dan methan $\left(\mathrm{CH}_{4}\right)$. Pada penelitian ini dilakukan rancang bangun tungku gasifikasi biomassa tipe counter-flow. Berdasarkan penelitian Kihedu, Yoshiie, Nunome, Ueki, Naruse [2], tungku gasifikasi tipe counter-flow merupakan kombinasi updraft dan downdraft gasifier. Tipe ini dipilih karena mampu meningkat Low Heating Value (LHV) dan mengurangi kandungan tar dari biomassa MSW yang dibakar. Municipal Solid Waste (MSW) ini akan dibentuk menjadi biomassa sebagai bahan bakar.

\section{METODE PENELITIAN}

\subsection{Bahan Penelitian}

Bahan digunakan pada penelitian ini adalah bahan bakar sampah padat perkotaan (MSW) dalam bentuk biomassa pelet dengan ukuran panjang 8,5 $\mathrm{mm}$ dan diameter $6,5 \mathrm{~mm}$ serta densitas $1,1 \mathrm{~g} / \mathrm{cm} 3$. MSW yang digunakan adalah sampah plastik, serbuk kayu, dan kertas. 


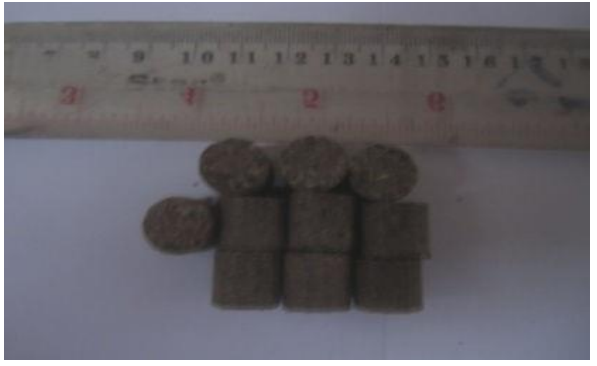

Gambar 2. Biomassa pellet MSW

\subsection{Perancangan Tungku Gasifikasi}

Perancangan tungku gasifikasi tipe counter-flow mengacu kepada rancangan tungku gasifikasi kihedu et al. [2]. Rancangan tungku gasifikasi dapat dilihat pada Gambar 3. Konsep dasar dari perancangan tungku gasifikasi tipe counter-flow ini adalah dengan melihat prinsip kerja dari tungku tersebut, dimana tungku ini merupakan kombinasi updraft dan downdraft gasifier.

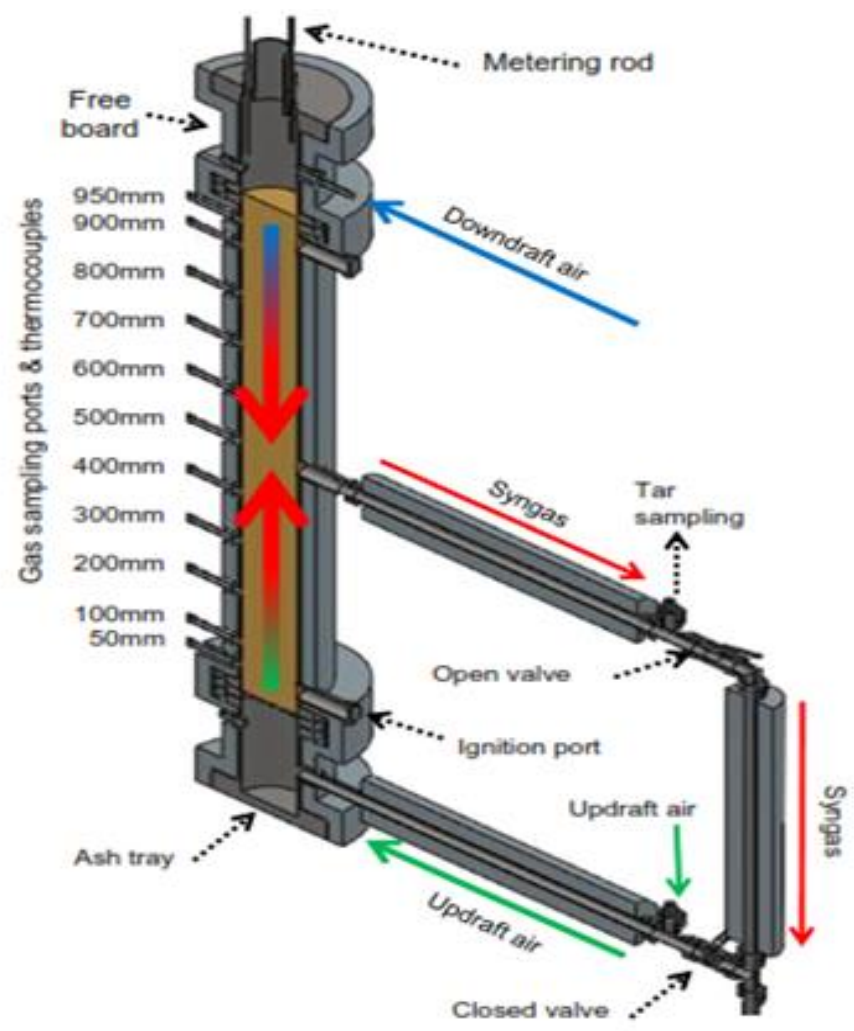

Gambar 3. Rancangan Tungku Gasifikasi Biomassa Tipe Counter-Flow

Selama proses pembakaran, udara downdraft dipasok ke reaktor sedangkan katup syngas bawah dibuka dan katup syngas tengah ditutup. Setelah mencapai kondisi tunak, yaitu stabilisasi suhu reaktor dan komposisi syngas. Mode operasi reaktor diubah dari downdraft ke counter-flow dengan menutup katup syngas bawah dan membuka katup syngas tengah. Tungku gasifikasi jenis ini menargetkan pada peningkatan LHV gas sekaligus mengurangi generasi tar, sehingga memudahkan pengaturan bagian pembakaran gas hasil gasifikasi [2].

\subsection{Variabel Penelitian}

Sebagai variabel penelitian adalah laju aliran udara (downdraft air/ updraft air) yaitu pada 12 ltr/menit/ $4 \mathrm{ltr} /$ menit, $8 \mathrm{ltr} / \mathrm{menit} / 8 \mathrm{ltr} /$ menit, $4 \mathrm{ltr} / \mathrm{menit} / 12$ ltr/menit.

\subsection{Pengujian Tungku Gasifikasi}

\subsubsection{Parameter Teknik Penelitian}

Sesuai dengan salah satu tujuan penelitian yaitu untuk mengevaluasi secara teknis terhadap tungku gasifikasi yang akan dibuat maka diperlukan 
parameter-parameter yang menjadi pokok penelitian. Parameter teknik yang diteliti adalah sebagai berikut: (1) Waktu penyalaan awal (startup time) merupakan waktu yang dibutuhkan oleh tungku gasifikasi untuk memproduksi syngas secara sempurna dari awal tungku ini dinyalakan. Atau dengan kata lain adalah waktu dari tungku dinyalakan sampai syngas bisa terbakar sempurna di burner; (2) Waktu operasi (operation time) merupakan waktu sejak syngas terbakar sempurna pada burner sampai nyala api pembakaran syngas pada burner mati; (3) Temperatur nyala pembakaran gas, merupakan temperatur api yang dihasilkan oleh proses gasifikasi; (4) Tingkat konsumsi bahan bakar (fuel comsumption rate) merupakan banyaknya bahan bakar yang dipakai oleh tungku gasifikasi tersebut, dihitung dengan persamaan:

$$
F C R=\frac{\text { Berat MSW yang dipakai }(\mathrm{kgf})}{\text { Waktu opersi }(\text { jam })}
$$

(5) Laju pemakaian bahan bakar merupakan perbandingan antara jumlah bahan bakar yang digunakan dalam pengujian dengan waktu operasional.

$\dot{m}=\frac{\text { m.bahan bakar-m.sisa pembakaran }}{\text { waktu operasional }}$

\subsubsection{Prosedur Pengujian}

Prosedur pengujian unjuk kerja tungku ini adalah sebagai berikut: (1) Selama periode star-up, $0,5 \mathrm{~kg}$ bahan bakar dimasukkan ke dalam reaktor; (2) Bahan bakar dinyalakan melalui ignition port dengan menggunakan propane burner hingga menyala seluruhnya (pre-heating); (3) Pada periode ini, udara downdraft dipasok pada $20 \mathrm{~L} /$ menit sedangkan katup syngas bawah dibuka dan katup syngas tengah ditutup; (4) Ketika suhu sekitar 250$300^{\circ} \mathrm{C}$, bahan bakar dimasukkan kembali hingga ketinggian 1000 mm kemudian tutup reaktor; (5) Setelah mencapai kondisi tunak, yaitu stabilisasi suhu reaktor dan komposisi syngas, lakukan pengukuran temperature nyala api; (6) Mode operasi reaktor diubah dari downdraft ke counter flow dengan menutup katup syngas bawah dan membuka katup syngas tengah; (7) Bersamaan, udara updraft disediakan 4L/menit dan udara downdraft berkurang menjadi $12 \mathrm{~L} / \mathrm{min}$. Dengan mempertahankan total pasokan udara, lakukan pengambilan sampel, pembacaan temperatur pada data logger, serta pengukuran temperatur nyala api setelah stabilisasi komposisi temperatur reaktor dan syngas; (8) Lakukan prosedur 1 sampai 8 dengan menggunakan variasi laju aliran udara 12 ltr/menit/ 4 ltr/menit, 8 ltr/menit/ 8 ltr/menit, 4 ltr/menit/ 12 ltr/menit.

\section{HASIL DAN PEMBAHASAN}

\subsection{Desain Konseptual}

Desain konseptual tungku gasifikasi dapat dilihat pada Gambar 4. Pada rancangan ini terdapat kombinasi saluran udara yang berasal dari atas dan bawah tungku (up-draft dan downdraft).

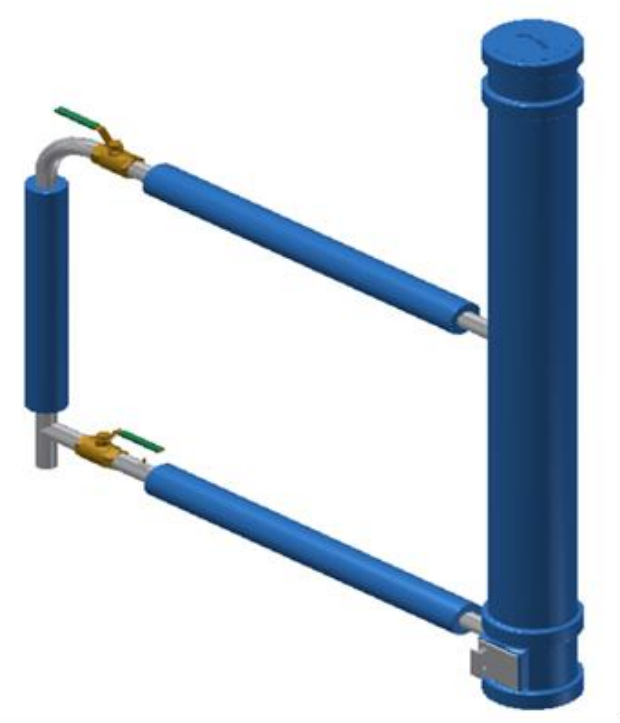

Gambar 4. Desain Konseptual Tungku Gasifikasi Biomassa Tipe Counter-Flow

\subsection{Perakitan alat}

Bagian-bagian tungku berupa Reaktor (gasifier), pipa galvanis, fitting, grate, katup disusun dan dirakit menjadi tungku gasifikasi tipe counter-flow. Yang pertama dilakukan adalah memasang grate dengan diameter $105 \mathrm{~mm}$ diatas ash tray (penampung abu). Kemudian letakkan reaktor gasifikasi diatas ash tray lalu kunci dengan baut 14 
mm. Untuk instalasi pemipaan, pipa galvanis 0,5 inchi dipasang dibagian tengah reaktor dan tengah ash tray. Pasang ball valve pada kedua ujung pipa galvanis. Lalu pasang elbow pada ball valve tengah untuk menghubungkan pipa galvanis horizontal dan pipa galvanis vertikal. Kemudian pasang equal tee untuk menghubungkan pipa galvanis vertikal dan ball valve. Berikut foto dari tungku gasifikasi yang telah selesai dibuat dan dirakit diperlihatkan pada Gambar 5.

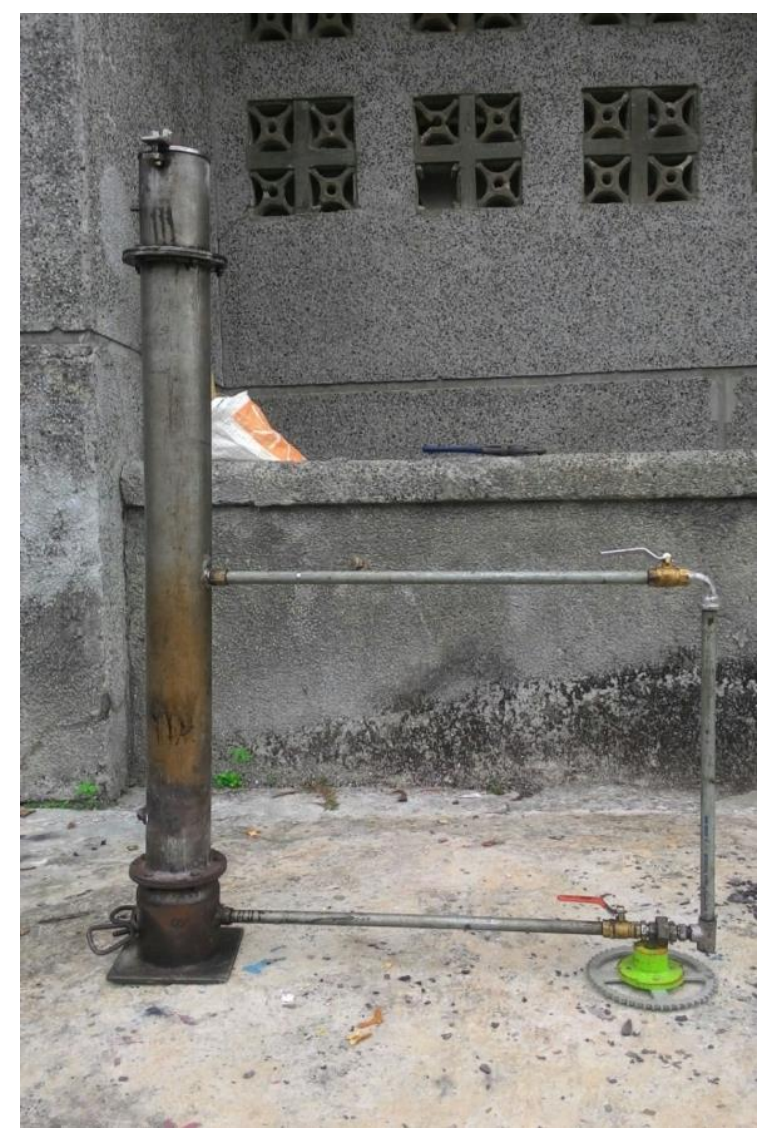

Gambar 5. Tungku Gasifikasi Tipe Counter-Flow

\subsection{Hasil Pengujian}

Tabel 1. Data hasil pengujian

\begin{tabular}{|c|c|c|c|c|c|}
\hline Bahan bakar & $\begin{array}{c}\text { Laju aliran udara } \\
\text { downdraft/updraft } \\
\text { (ltr/menit) }\end{array}$ & $\begin{array}{c}\text { M. Bahan bakar } \\
\text { (gram) }\end{array}$ & $\begin{array}{c}\text { M. } \\
\text { Arang } \\
\text { (gram) }\end{array}$ & $\begin{array}{c}\text { Starting } \\
\text { time } \\
\text { (menit) }\end{array}$ & $\begin{array}{c}\text { waktu operasi } \\
\text { (menit) }\end{array}$ \\
\hline \multirow{3}{*}{ MSW } & $12 \mathrm{lpm} / 4 \mathrm{lpm}$ & 1400 & 200 & 9 & 19 \\
\cline { 2 - 6 } & $8 \mathrm{lpm} / 8 \mathrm{lpm}$ & 1400 & 160 & 8,5 & 20 \\
\cline { 2 - 6 } & $4 \mathrm{lpm} / 12 \mathrm{lpm}$ & 1400 & 120 & 8 & 24 \\
\hline
\end{tabular}




\subsection{Analisa dan Pembahasan}

\subsubsection{Analisa Massa Sisa Pembakaran}

Berdasarkan Gambar 6 dapat diliihat bahwa massa sisa pembakaran paling sedikit terjadi pada pengujian dengan variasi laju aliran udara $4 \mathrm{lpm} / 12$ lpm (downdraft/ updraft) dengan masssa sisa pembakaran yaitu 120 gram. Massa sisa pembakaran semakin sedikit seiring dengan semakin sedikit udara downdraft yang diberikan sedangkan udara updraft semakin besar diberikan. Hal ini dapat dilihat pada variasi laju aliran udara 12 lpm/ 4 lpm (downdraft/ updraft) memiliki massa sisa pembakaran paling banyak yaitu 200 gram. Hal ini disebabkan panas dari area oksidasi tidak terbawa sempurna ke atas untuk area pirolisis dan untuk mengeringkan bahan bakar dibagian atas karena udara downdraft yang diberikan terlalu kencang. Sehingga laju pemakaian bahan bakar berlangsung tidak baik yang menyebabkan massa sisa pembakarannya menjadi banyak. Udara downdraft adalah udara yang diberikan kedalam reaktor menuju kebawah reaktor, sedangkan udara updraft adalah udara yang diberikan kedalam reaktor menuju keatas reaktor.

\subsubsection{Analisa Pengaruh Laju Aliran Udara terhadap Waktu}

Berdasarkan Gambar 7 terlihat laju aliran udara yang diberikan tidak terlalu berpengaruh terhadap waktu penyalaan awal atau bisa dikatakan relatif konstan. Waktu penyalaan awal terendah adalah pada laju aliran udara $12 \mathrm{lpm} / 4 \mathrm{lpm}$ (downdraft/ updraft) yaitu 9 menit. Sedangkan waktu penyalaan awal tercepat adalah pada laju aliran udara $4 \mathrm{lpm} / 12$ lpm (downdraft/ updraft) yaitu 8 menit. Dari Gambar 7 juga terlihat kenaikan waktu operasi tungku seiring menurunnnya udara downdraft yang diberikan sedangkan udara updraft yang diberikan semakin besar. Waktu operasi paling lama adalah 24 menit pada laju aliran udara $4 \mathrm{lpm} / 12 \mathrm{lpm}$ (downdraft/ updraft). Jadi dapat disimpulkan semakin besar udara updraft yang diberikan sedangkan udara downdraft semakin kecil maka waktu operasi tungku akan semakin lama. Namun, rasio udara dan bahan bakar harus tetap dibawah 1,5 (AFR $<1,5$ adalah gasifikasi). Dengan jumlah massa bahan bakar yang sama, waktu operasi yang lama membuktikan efisiensi tungku semakin baik.

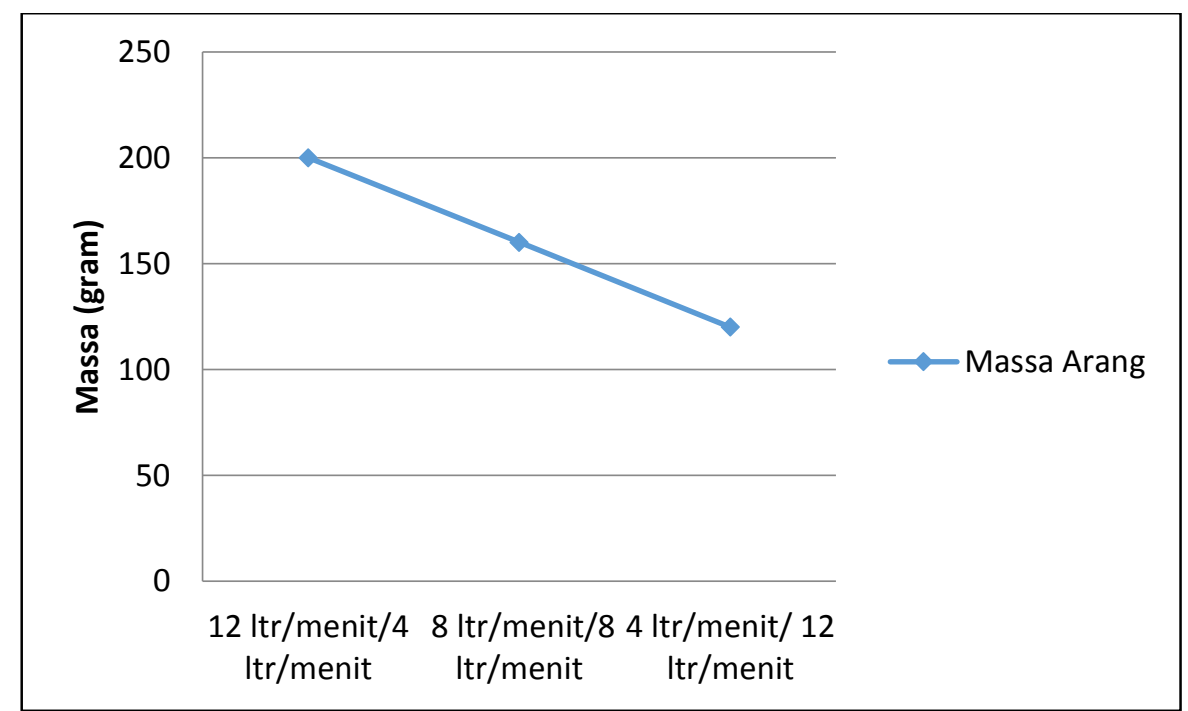

Gambar 6. Pengaruh laju aliran udara terhadap massa sisa pembakaran 


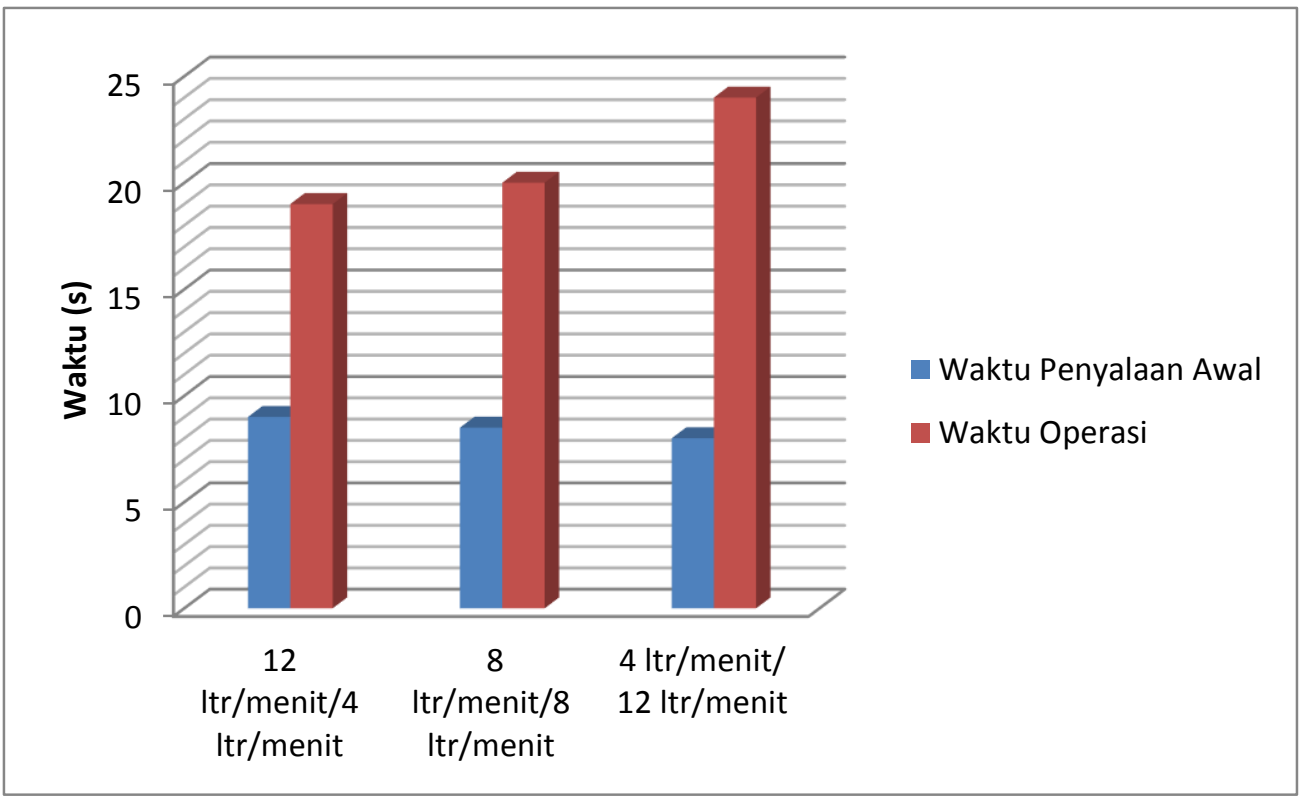

Gambar 7. Pengaruh laju aliran udara terhadap waktu

\section{KESIMPULAN}

(1) Bahan bakar municipal solid waste (MSW) bisa digunakan untuk proses gasifikasi dengan tungku gasifikasi tipe counter-flow; (2) Semakin kecil perbandingan laju aliran udara downdraft/ updraft maka laju pemakaian bahan bakar akan semakin besar, begitu juga sebaliknya. Laju pemakaian bahan bakar paling besar adalah pada laju aliran udara 4 lpm/ 12 lpm; (3) Semakin kecil perbandingan laju aliran udara downdraft/ updraft maka waktu operasional semakin lama, hal ini disebabkan laju pemakaian semakin besar, begitu juga sebaliknya. Waktu operasional paling lama adalah 24 menit; (4) Kinerja tungku gasifikasi paling optimal adalah pada variasi laju aliran udara $4 \mathrm{lpm} / 12 \mathrm{lpm}$.

\section{UCAPAN TERIMA KASIH}

Terima kasih diucapkan kepada Lembaga Penelitian dan Pengabdian Masyarakat Universitas Andalas, atas terlaksana penelitian ini pada Skim Penelitian Dosen Pemula Universitas Andalas Tahun 2016.

\section{DAFTAR PUSTAKA}

[1] Y. Ruslinda, Veronika. Satuan Timbulan dan Komposisi Sampah Industri Kota Padang. Jurnal Teknik Lingkungan UNAND 2013. Padang: Teknik Lingkungan Universitas Andalas.

[2] J. H. Kihedu, R. Yoshiie, Y. Nunome, Y. Ueki, I. Naruse, "Counter-flow air gasification of woody biomass pellets in the auto-thermal packed bed reactor". Fuel, 117, pp. 1242-1247, 2014.

[3] H. Knoef, Ed. Handbook Biomass Gasification. BTG Biomass Technology Group, 2005

[4] http://wahyudin27.blogspot.com/2012/12/siste m-pengelolaan-sampah-perkotaan.html

[5] http://www.jie.or.jp/biomass/AsiaBiomassHan dbook/Indonesian/Part-4_I.pdf

[6] S. Martosudirjo, Potensi Pengolahan Limbah Kayu dan Biomassa Lainnya Sebagai Sumber Listrik di Indonesia. Pustlitbang Fisika Terapan-LIPI, Bandung: Corporation, Aurora, Colorado, 1990 